BMJ Paediatrics Open

\section{Assessing the quality of paediatric antibiotic prescribing by community paediatricians: a database analysis of prescribing in Lombardy}

Daniele Piovani, ${ }^{1}$ Antonio Clavenna, ${ }^{1}$ Massimo Cartabia, ${ }^{1}$ Angela Bortolotti, ${ }^{2}$ Ida Fortino, ${ }^{2}$ Luca Merlino, ${ }^{2}$ Maurizio Bonati ${ }^{1}$
To cite: Piovani D, Clavenna A, Cartabia M, et al. Assessing the quality of paediatric antibiotic prescribing by community paediatricians: a database analysis of prescribing in Lombardy. BMJ Paediatrics Open 2017;1:e000169. doi:10.1136/ bmjpo-2017-000169

Received 27 June 2017 Revised 28 July 2017 Accepted 7 August 2017

\section{(DrossMark}

${ }^{1}$ Department of Public Health, Laboratory for Mother and Child Health, IRCCS - Istituto di Ricerche farmacologiche "Mario Negri", Milan, Italy

${ }^{2}$ Regional Health Ministry, Lombardy Region, Milan, Italy

Correspondence to Dr Daniele Piovani; daniele. piovani@marionegri.it

\section{ABSTRACT}

Objective To evaluate the quality of paediatricians' antibiotic prescribing using administrative databases. Methods The data source was the database of reimbursed prescriptions of the Lombardy Region, Italy. Children 1-13 years were included. An index prescription was defined as the first antibiotic prescription during a year period (2011) that occurred without previous, recent, antibiotic prescriptions or hospital or emergency department admissions. The A indicator was the percentage of children, cared for by paediatricians, receiving amoxicillin at the index prescription (minimum target $50 \%)$. The $B$ indicator was the percentage of children receiving exclusively non-penicillin antibiotics in unrelated infection episodes (maximum target 10\%). Indicators were evaluated for each prescriber and geographical area.

Results Overall 424280 children (cared for by 1164 paediatricians) received an index prescription and were included in the study. Amoxicillin alone was prescribed at the index prescription only to $23.6 \%$ of children (7.9\%-46.3\% within different areas of the region). The percentage of paediatricians who reached the target for the quality indicators was low $12.8 \%$ A indicator; $54.0 \%$ $B$ indicator; $11.3 \%$ both). Almost half of the paediatricians $(44.5 \%)$ showed inadequate quality of antibiotic prescribing, failing to reach the target for both indicators. Quality of prescribing was about four times worse in high prescribers and younger paediatricians. A geographical cluster of paediatricians reaching the target for both indicators was identified. These paediatricians had, for several years, previously been involved in educational programme.

Conclusions Quality of prescribing was generally unsatisfactory, but increased in a group of paediatricians previously involved in educational interventions and increased with increasing age. Further studies are warranted in order to validate these promising indicators as a benchmarking tool in other studies, when diagnosis is unknown.

\section{INTRODUCTION}

The lack of appropriate use of antibiotics and antibiotic resistance have been worldwide

\section{What is already known on this topic?}

Antibiotics are overused in outpatient children in Italy more often compared with other European countries.

- The paediatrician's prescribing attitude has been identified as one of the main determinants of differences in antibiotic prevalence at the area level.

- The association between paediatricians characteristics and the qualitative profile of antibiotic prescribing is a scantly studied topic.

\section{What this study hopes to add?}

- The study investigates the quality of paediatricians' antibiotic prescribing to outpatient children by using administrative databases and a few newly identified indicators.

- Almost half of the paediatricians showed inadequate quality of antibiotic prescribing, failing to reach the target for both quality indicators.

- Quality of prescribing was significantly worse in the youngest paediatricians, in those prescribing more antibiotics and in those who did not receive educational interventions.

problems for the last few decades. ${ }^{1}$ Unnecessary antibiotic prescriptions for viral diseases, and the use of second choice therapies for certain conditions, can increase antibiotic resistance also in the community setting (ie, Streptococcus pneumoniae resistance to macrolides). ${ }^{12}$ Since children are among the most exposed to this drug class, rational antibiotic prescribing in paediatrics is of paramount importance. ${ }^{3}$

Antibiotics are overused in outpatient children in Italy more often compared with other European countries. ${ }^{4}$ Frequent prescriptions of second choice treatments and wide heterogeneity in prevalence at different geographic 
area levels (34.0\%-67.9\% among healthcare districts) have been identified and described. ${ }^{5-7}$ Amoxicillin is the first-line treatment for respiratory infections in children in the community setting, and we previously used it as a proxy of appropriateness in Italy, with large differences in prevalence ranging from $8.7 \%$ to $28.1 \%$ among regions and from $7.1 \%$ to $48.0 \%$ among local health units (LHUs). ${ }^{58}$ The percentage of children treated with amoxicillin was later proposed as an indicator of the quality of prescribing (amoxicillin index) by de Bie $e t a l^{9}$

The paediatrician's prescribing attitude has already been identified as one of the main determinants of differences in antibiotic prevalence at the area level. ${ }^{7}$ Despite this, the association between the amount of antibiotics prescribed and the qualitative profile is a scantly studied topic. Moreover, most epidemiological studies on drug prescription patterns are based on administrative databases that rarely contain the indication for the prescription. Thus, evaluating appropriateness on a selected population by developing specific quality indicators may be a useful proxy for the quality of antibiotic prescribing.

The aim of this study was to evaluate the quality of paediatricians' antibiotic prescribing through administrative databases by analysing a selected population of children and by using indicators at the population level.

\section{METHODS}

\section{The Italian national health service (NHS)}

Italian healthcare is provided for free or at a nominal cost through a network of LHUs. Every Italian resident is registered with a family (paediatric or general) practitioner. Children are assigned to a paediatrician until they are 6 years old; afterwards, the parents can choose to register a child with a general practitioner. Most children are assigned to a paediatrician until 14 years old; afterwards, they have to be assigned to a general practitioner. A national formulary is available in which drugs are categorised into two classes: class A includes essential drugs that patients do not have to pay for and class C contains drugs not covered by the NHS (eg, contraceptives, non-steroidal anti-inflammatory drugs and dermatologic drugs).

\section{DATA SOURCE}

The data source was the database of the Lombardy Region, which is routinely updated for administrative and reimbursement reasons. The region is divided into eight LHUs, which are further divided into two to seven smaller areas called ASSTs (social health territorial units), for a total of 27 ASSTs. The three ASSTs referring to the city of Milan are considered as a unique ASST in this study. Only drugs reimbursed by the NHS are included in the database. Anonymous data were provided by the regional health ministry of the Lombardy Region. All drugs were classified according to the Anatomical Therapeutic Chemical classification system.

\section{INDEX PRESCRIPTION}

An index prescription was defined as the first antibiotic prescription in 2011 that occurred without: an antibiotic prescription in the previous 60 days, a hospital admission in the previous 60 days and an emergency department admission in the previous 14 days.

\section{INCLUSION CRITERIA}

Children and adolescents 1-13 years old who received at least one index prescription during 2011 were included.

\section{EXCLUSION CRITERIA}

Children who received seven or more antibiotic prescriptions $\left(95^{\circ}\right.$ percentile of the distribution of annual prescriptions per children at 4 years of age, the age with the most antibiotic prescriptions) in the 365 days either before or after the index prescription were excluded (31 899; 2.7\% of the resident population). These criteria ensured that children included in the study were not patients with chronic infections, or with other conditions requiring recurrent antibiotic courses.

Children who were not residents in the Lombardy Region from the year before the index prescription until the end of the follow-up period were excluded. Children in the first year of life were excluded because of possible treatments for bronchiolitis.

Children who were residents in one of two specific ASSTs were excluded because data on emergency department admissions were not available.

Children who were not cared for by a family paediatrician were excluded $(59875 ; 5.0 \%$ of the resident population) and those who were cared for by paediatricians with less than 98 patients $\left(10^{\circ}\right.$ percentile of the distribution of the number of children per family paediatrician) were excluded in order to have a more homogeneous population of paediatricians (1760 patients; $0.1 \%$ ).

Of the 1002006 resident children, 424280 (cared for by 1164 paediatricians) satisfied the inclusion and exclusion criteria and were included in the study.

\section{MEASURES}

The percentage distribution of antibiotic prescriptions by class and active substance (for amoxicillin and amoxicillin clavulanate) was investigated.

\section{DATA ANALYSES}

Each child or adolescent, and paediatrician, was followed for 1 year from the index prescription. The profile of antibiotic prescriptions was estimated at the population level:

1. at the index prescription,

2. in unrelated infective episodes, identified by a new antibiotic prescription occurring 30 days or more after the index prescription. 


\section{QUALITY INDICATORS}

- The A indicator was the proportion of children who received amoxicillin by the paediatrician at the index prescription. From the prospective evaluation of data in paediatric ambulatory care in Italy it is known that more than half of the systemic antibiotics are prescribed for pharyngotonsillitis $(26.9 \%)$ and acute otitis media (AOM; 24.4\%). ${ }^{10}$ In case of bacterial AOM and pharyngotonsillitis, amoxicillin is the first-line therapy because, respectively, Streptococcus pyogenes (always sensible) $^{11-13}$ and $S$. pneumoniae (highly sensible in $90 \%$ of cases $^{1114-17}$ ) are the pathogens that are able to cause the most important complications. Amoxicillin is the first-line therapy also in case of scarlet fever caused by $S$. pyogenes (3\% of antibiotic prescriptions $\left.^{10}\right)$, uncomplicated pneumonia ${ }^{18} 19$ and sinusitis. ${ }^{10}{ }^{20}$ Hence we estimated that at least $50 \%$ of patients treated with an antibiotic should be initially treated with amoxicillin (target for the A indicator).

- The B indicator was the proportion of children who received cephalosporins or macrolides, exclusively, by the paediatrician for every unrelated infective episode. The maximum target percentage was set at $10 \%$. The rationale of this criterion was that self-reported hypersensitivity to beta-lactams in children varies from $1.7 \%$ to $7.9 \% .{ }^{21-23}$ We are therefore confident that in no more than $10 \%$ of children hypersensitivity can justify the exclusive prescription of second choice treatments throughout the year.

Number of paediatricians that reached the target for the A or B indicators has been estimated also at the ASST level. Number of paediatricians that reached the target for both indicators was also estimated.

The geographical distribution of paediatricians in respect to the quality indicators was represented in choropleth maps. Clusters and outlier values were calculated by using the Anselin Local Moran's I statistic. ${ }^{24}$

The paediatricians were categorised based on the distribution of the average number of antibiotic prescriptions per patient, considering all their patients $\geq 1$ to 13 years old: low prescriber corresponded to the arithmetical mean minus the SD $(\mathrm{y}<\bar{x}-s d$, lower than $0.74)$, a mean prescriber to $\bar{x}-s d<\mathrm{y}<\bar{x}(0.74$ to 1.44$)$ and high prescriber to $\mathrm{y}>\bar{x}+s d$ (higher than 1.44). The same criteria were used for classifying paediatricians in respect to age (young $\leq 44$; adult $45-59$ and elderly $\geq 60$ ) and in respect to number of patients (low $\leq 645$; mean 646-1076 and high $\geq 1077)$. The quality of prescription (A and $\mathrm{B}$ indicators) was estimated in the different groups of paediatricians (low/mean/high prescriber). Cochran-Mantel-Haenszel test for trend was used to test the difference among low, mean and high prescribers. A multivariate logistic regression analysis was performed at the paediatrician level on the likelihood of reaching the target for both A and B indicators. The paediatricians' covariates considered were: sex, age, prescribing pattern in respect to quantity of antibiotic prescriptions, number of children cared for by each paediatrician and area of residence. The variables entered the model by a stepwise selection with a significance $\alpha=0.05$.

The statistical analyses were performed with SAS V.9.5 and the cartographic representations and spatial analyses with ArcMap V.10.5.

\section{RESULTS}

Of the 1002006 children 1-13 years old in our sample, $49.9 \%$ received at least an antibiotic prescription. Prevalence decreased with increasing age from $63.9 \%$ (1-5 years old) to $30.4 \%$ (10 -12 years old).

Overall 1164 paediatricians cared for a median of 857 children (IQR 736-1012). Paediatricians were mostly females $(75.3 \%)$, and the median age was 53 years old (IQR 48-56).

\section{PRESCRIPTION PROFILE}

Of the 424280 children included in the study with an index prescription: $146582(34.5 \%)$ received one antibiotic prescription, $115541(27.2 \%)$ received two prescriptions and 162157 (38.2\%) received three to six prescriptions in the year of follow-up. Penicillins were prescribed in $68.6 \%$, macrolides in $16.5 \%$ and cephalosporins in $13.3 \%$ of cases at the index prescription. The most prescribed active substance was amoxicillin clavulanate at any age, table 1 . Amoxicillin was prescribed at the index prescription to $23.6 \%$ of children, and this indicator varied widely at the area level ranging from $7.9 \%$ to $46.3 \%$ among ASSTs. In none of the ASST the percentage of children receiving amoxicillin at the index prescription reached the target of the $50 \%$.

A total of 258681 children $(61.0 \%)$ had one or more unrelated infection episodes 30 days or more after the index prescription. The majority of these children $(208,768 ; 80.2 \%)$ received different antibiotics during the year; $12.1 \%$ of children (31 192) received exclusively second choice treatments such as macrolides and cephalosporins and $7.7 \%$ (19914) exclusively amoxicillin. These percentages varied widely between ASSTs: from $8.2 \%$ to $22.0 \%$ for the former indicator and from $1.4 \%$ to $21.8 \%$ for the latter.

\section{PAEDIATRICIANS}

Each paediatrician prescribed amoxicillin at the index prescription to a median of $21.1 \%$ (IQR 9\%-37\%) of patients and prescribed only non-penicillin antibiotics in unrelated infective episodes to $9.3 \%$ (IQR 6\%-14\%) of patients.

The percentage of paediatricians who reached the target of having prescribed amoxicillin at the index prescription to at least $50 \%$ of patients (A indicator) was $12.8 \%$. The percentage of paediatricians who reached the target of having prescribed exclusively non-penicillin antibiotics in unrelated infection episodes to less than $10 \%$ of patients (B indicator) was 54.0\%. Overall, 131 
Table 1 Percentage distribution of children at the index prescription by active substance and age strata

\begin{tabular}{|c|c|c|c|c|c|c|c|c|c|c|}
\hline & \multicolumn{2}{|c|}{$\geq 1$ year } & \multicolumn{2}{|c|}{ 2-5years } & \multicolumn{2}{|c|}{$6-9$ years } & \multicolumn{2}{|c|}{ 10-13years } & \multicolumn{2}{|c|}{ Total } \\
\hline & $\mathbf{n}$ & $\%$ & $\mathbf{n}$ & $\%$ & $\mathbf{n}$ & $\%$ & $\mathbf{n}$ & $\%$ & $\mathbf{n}$ & $\%$ \\
\hline $\begin{array}{l}\text { Amoxicillin } \\
\text { clavulanate }\end{array}$ & 25858 & 41.1 & 91630 & 46.0 & 51146 & 46.3 & 21699 & 42.2 & 190333 & 44.9 \\
\hline Amoxicillin & 22350 & 35.5 & 46730 & 23.4 & 21789 & 19.7 & 9696 & 18.9 & 100565 & 23.7 \\
\hline Clarithromycin & 3286 & 5.2 & 15838 & 7.9 & 11136 & 10.1 & 6581 & 12.8 & 36841 & 8.7 \\
\hline Azithromycin & 2577 & 4.1 & 13835 & 6.9 & 9885 & 8.9 & 6298 & 12.3 & 32595 & 7.7 \\
\hline Cefixime & 2499 & 4.0 & 8765 & 4.4 & 4816 & 4.4 & 2368 & 4.6 & 18448 & 4.3 \\
\hline Cefaclor & 2917 & 4.6 & 9087 & 4.6 & 3602 & 3.3 & 817 & 1.6 & 16423 & 3.9 \\
\hline Cefpodoxime & 1772 & 2.8 & 6797 & 3.4 & 3863 & 3.5 & 1572 & 3.1 & 14004 & 3.3 \\
\hline Ceftibuten & 836 & 1.3 & 2595 & 1.3 & 1237 & 1.1 & 423 & 0.8 & 5091 & 1.2 \\
\hline Fosfomycin & 47 & 0.1 & 862 & 0.4 & 837 & 0.8 & 389 & 0.8 & 2135 & 0.5 \\
\hline Cefuroxime & 195 & 0.3 & 782 & 0.4 & 531 & 0.5 & 311 & 0.6 & 1819 & 0.4 \\
\hline Other & 291 & 0.5 & 1.087 & 0.5 & 786 & 0.7 & 711 & 1.4 & 2875 & 0.7 \\
\hline >one antibiotic & 293 & 0.5 & 1.392 & 0.7 & 951 & 0.9 & 515 & 1.0 & 3151 & 0.7 \\
\hline Total & 62921 & 100 & 199400 & 100 & 110579 & 100 & 51380 & 100 & 424280 & 100 \\
\hline
\end{tabular}

paediatricians $(11.3 \%)$ reached the target for both indicators (covering $11.2 \%$ of the regional child population). On the contrary, 518 paediatricians $(44.5 \%$, covering $44.8 \%$ of the regional child population) showed inadequate quality of antibiotic prescribing, not reaching the target for either of the two indicators.

High prescribers were less likely to prescribe amoxicillin at the index prescription $\left(\chi^{2}\right.$ for trend $\left.\mathrm{p}=0.002\right)$ and were more likely to prescribe only non-penicillin antibiotics $\left(\chi^{2}\right.$ for trend $\left.\mathrm{p}<0.001\right)$, table 2 . The univariate analysis showed that paediatricians with an adequate quality of antibiotic prescribing (reaching the target for both the $\mathrm{A}$ and $\mathrm{B}$ indicators) were more likely to be: low prescribers, females, elderly and resident in a specific cluster of high values identified by the spatial analyses in a urban area in north of Milan, figure 1 and table 3 .

At the geographic level, there was a huge variability in quality of prescribing, with a percentage of paediatricians who reached the target for the A indicator ranging from $0 \%$ to $53.0 \%$ and for the B indicator ranging from $9.1 \%$ to $84.8 \%$ between ASSTs, figure 1. In three ASSTs, no paediatrician reached the targets and only in one ASST more than $50 \%$ of paediatricians did.

The multivariate analysis showed that the paediatrician determinants of adequate quality of antibiotic prescribing were the geographic factor, being a low prescriber and being elderly, table 4 . Sex and the number of patients were not relevant factors in the multivariate model and were excluded by the stepwise selection of covariates.

\section{DISCUSSION}

To the best of our knowledge, this is the first study evaluating the quality of paediatricians' antibiotic prescribing through an administrative database in Italy.

In order to reach our objective, we selected, and monitored, children who were receiving a course of treatment not preceded by any antibiotic prescription and/or hospitalisation in the preceding 2 months. In this regard, we were confident that, at least for the index prescription,

Table 2 Distribution of two quality indicators among the paediatricians ordered by type of prescriber

\begin{tabular}{|c|c|c|c|c|c|c|c|c|c|c|c|c|}
\hline \multirow{2}{*}{$\begin{array}{l}\text { Type of } \\
\text { paediatrician }\end{array}$} & \multicolumn{4}{|c|}{ Indicator $A^{*}$} & \multicolumn{4}{|c|}{ Indicator B† } & \multicolumn{4}{|c|}{$\begin{array}{l}\text { Adequate quality according to } \\
\text { adherence to both indicators }\end{array}$} \\
\hline & No & Yes & Total & $\%$ Yes & No & Yes & Total & $\%$ Yes & No & Yes & Total & $\%$ Yes \\
\hline Low prescriber & 121 & 30 & 151 & 19.9 & 43 & 108 & 151 & 71.5 & 122 & 29 & 151 & 19.2 \\
\hline Mean prescriber & 751 & 107 & 858 & 12.5 & 395 & 463 & 858 & 54.0 & 765 & 93 & 858 & 10.8 \\
\hline High prescriber & 143 & 12 & 155 & 7.7 & 98 & 57 & 155 & 36.8 & 146 & 9 & 155 & 5.8 \\
\hline Total & 1015 & 149 & 1164 & 12.8 & 536 & 628 & 1164 & 54.0 & 1033 & 131 & 1164 & 11.3 \\
\hline p Valuef & & & & 0.002 & & & & $<0.001$ & & & & $<0.001$ \\
\hline
\end{tabular}

${ }^{*}$ Paediatricians who prescribe amoxicillin at the index prescription to at least $50 \%$ of their patients.

†Paediatricians who prescribe only non-penicillin antibiotics in unrelated infective episodes to a maximum of $10 \%$ of their patients included in the study.

‡Cochran-Armitage trend test. 

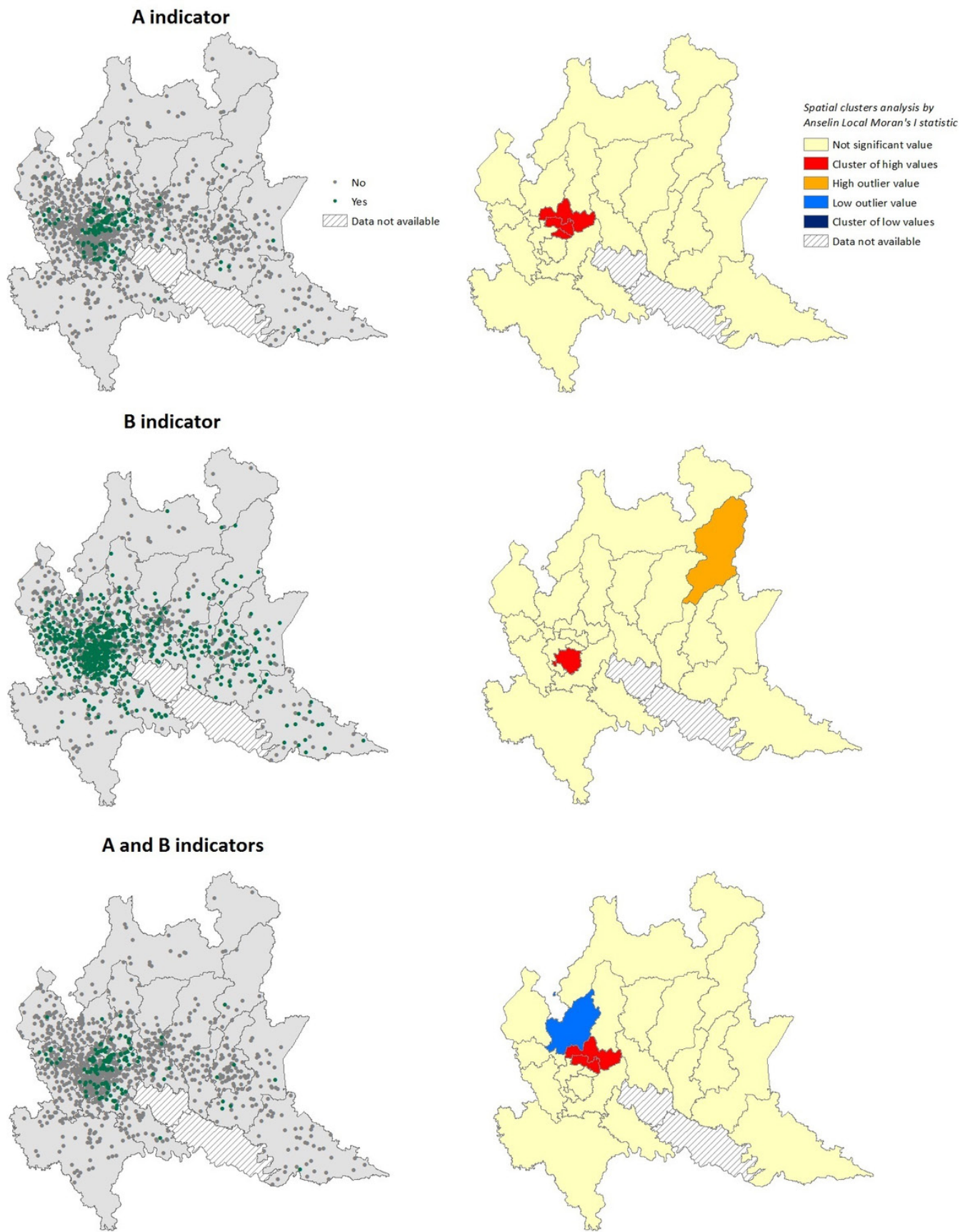

Figure 1 Distribution of the paediatricians who prescribed amoxicillin alone at the index prescription to at least $50 \%$ of their patients included in the study (A indicator) and of the percentage of paediatricians that prescribed exclusively non-penicillin antibiotics in different infection episodes to more than $10 \%$ of their patients included in the study (B indicator). Spatial cluster analysis of the distribution of the indicators by ASST.

amoxicillin would be prescribed to the majority of children in our sample. At the population level, this was not found, and only $24 \%$ of children (less than half of expected) received amoxicillin as the index prescription. Despite the fact that the Lombardy Region is among the settings with a relatively low antibiotic prescription rate in Italy, the above findings reveal a poor average quality of prescriptions.

In other international studies, the amoxicillin index was found to be very heterogeneous, ${ }^{4925} 26$ ranging from $21.1 \%$ in Germany to $46.8 \%$ in the Netherlands, even if in Germany phenoxymethylpenicillin appropriately accounts for a significant additional proportion of prescriptions, differently from Italy. First-line penicillins were found to be scantly prescribed in Italy in a recent study comparing six different countries: from $64.8 \%$ of antibiotic prescriptions in Norway to $24.1 \%$ in the Pedianet database (Italy) and 8\% in the Lazio Region (Italy). ${ }^{27}$ We were not able to find studies that evaluated the paediatricians' quality of prescribing at the prescriber level with criteria comparable to those used in our study. Only one French study investigated the qualitative profile of 
Table 3 Paediatricians characteristics and their association with reaching the target for both the $A$ and $B$ quality indicators (adequate quality)

\begin{tabular}{llll}
\hline & & \multicolumn{2}{c}{ Paediatricians (\%) } \\
\cline { 3 - 4 } Paediatricians & characteristics & $\begin{array}{l}\text { Adequate } \\
\text { quality* }\end{array}$ & p Value† \\
\hline Type of & Low prescriber & 19.2 & $<0.001$ \\
prescriber & Mean prescriber & 10.8 & \\
& High prescriber & 5.8 & \\
Sex & Female & 9.8 & $<0.001$ \\
& Male & 15.6 & \\
Age (years) & $\leq 44$ & 4.7 & $<0.001$ \\
& $45-59$ & 11.4 & \\
Number of & $\geq 60$ & 17.0 & \\
patients & Low $\leq 645$ & 8.2 & 0.031 \\
& Mean 646-1076 & 12.9 & \\
Area of & High $\geq 1077$ & 7.1 & \\
residence & Urban area at north & 39.5 & $<0.001$ \\
& of Milan $\ddagger$ & & \\
& Other areas of the & 8.2 & \\
\hline
\end{tabular}

*Paediatricians who reached the target for the A and B quality indicators.

$+\chi^{2}$ test.

$\ddagger$ This area includes those that are part of the cluster identified in figure 1.

community paediatricians at the prescriber level, finding cefpodoxime as the most prescribed antibiotic, and amoxicillin representing $25 \%$ of the antibiotic prescriptions. ${ }^{28}$ Other studies evaluated the appropriateness of antibiotic

Table 4 Logistic multivariate regression model for the likelihood of each paediatrician of reaching the target for both the A and B quality indicators according to sex, age, prescribing pattern in respect to quantity of antibiotic prescriptions, number of children cared for by each paediatrician and area covered by paediatricians' offices

\begin{tabular}{llll}
\hline Covariates & & OR $^{*}$ & $\mathbf{9 5 \%} \mathbf{C l}$ \\
\hline Type of & Low prescriber & 4.61 & (1.99 to 10.69) \\
prescriber & Mean prescriber & 2.26 & (1.08 to 4.75) \\
& High prescriber & 1.00 & - \\
Age (years) & $\leq 44$ & 1.00 & \\
& $45-59$ & 2.41 & $(1.07$ to 5.46$)$ \\
& $\geq 60$ & 3.98 & $(1.58$ to 10.04) \\
Area & Urban area at & 8.64 & $(5.47$ to 13.66) \\
$\begin{array}{l}\text { covered by } \\
\text { paediatricians' } \\
\text { offices }\end{array}$ & north of Milan $\dagger$ & & \\
& Other areas of the & 1.00 & - \\
\hline
\end{tabular}

*Sex and number of children cared for by each paediatrician did not enter the model according to the stepwise selection.

†Cluster of high values identified in figure 1, according to the Anselin Local Moran's I statistic. prescribing at the population level or comparing different type of prescriber. ${ }^{29} 30$ In these studies, the first-choice antibiotics were prescribed in $50 \%-85 \%$ of episodes, and there were wide qualitative differences among general practitioners and paediatricians. ${ }^{29} 30$

In our study, the most prescribed antibiotic was amoxicillin-clavulanate at any age, even though it is less palatable and tolerable than amoxicillin alone. ${ }^{31}$ It is very likely that this happens for fear of infections caused by beta-lactamase producing bacteria. This is unjustified by the evidence, which shows that beta lactamase producing bacteria in AOM or sinusitis, for example, are those causing less severe complications and whose infections most commonly resolve spontaneously. ${ }^{141620}$

Different factors (eg, poor education, parental expectation of a prescription) may explain some of the qualitative and quantitative differences between Italy and other countries. It is likely that most of the differences observed in our study are due to the paediatricians' prescribing patterns. We already documented that in the areas where antibiotic prevalence is higher, high prescribing paediatricians are more frequent. ${ }^{7}$ In this regard, the current study adds relevant findings concerning quality of prescriptions.

The percentage of paediatricians with adequate quality of antibiotic prescribing was extremely low, and almost half of the paediatricians did not reach the target for both the $\mathrm{A}$ and $\mathrm{B}$ indicators. This means that almost half of the regional child population was treated with antibiotics that exposed them to greater potential risks. An impressive variability was found between ASSTs, with only one having more than $50 \%$ of paediatricians with good quality prescribing, and three ASSTs with no paediatricians reaching the target. It is quite striking that there were a few paediatricians who did not prescribe the recommended treatment at all at the index prescription to any of their patients.

When looking at the percentage of children receiving second-line treatments only (macrolides and/or cephalosporins, $\mathrm{B}$ indicator) in all the infection episodes, the average value was slightly above the threshold expected on the basis of the frequency of beta-lactams hypersensitivity. Also, in this case, a huge variability was found between ASSTs, with some geographical settings exceeding $20 \%$. Cephalosporins are hardly ever prescribed in the community setting in most of the north European countries and do not present significant benefits over amoxicillin in most cases. ${ }^{4}$ Macrolides are very susceptible to developing resistance and should be used in selected cases or in hypersensitive patients. ${ }^{33}$

Quantity of antibiotics prescribed was associated with quality. The proportion of paediatricians reaching the target for both indicators was almost fourfold higher in the low prescribing group compared with the high prescribing group. Considering, as an additional criteria of 'good practice', the limited prescription of antibiotics, only 29 out of 1164 paediatricians satisfied both A and B indicators and were also 'low prescribers'. Additionally, 
146 out of 1164 paediatricians (12,5\%) were high prescribers and did not reach the target for the quality indicators. Moreover, the Lombardy Region is among the regions with the highest amoxicillin index in Italy, and it is thus expected that in other regions the quality indicators at the paediatrician level will be worse.

The study highlighted a specific cluster of higher quality antibiotic prescriptions in an urban area slightly north of Milan. This confirms a long-term effect of a continuous educational intervention (in the period 2004-2008) on a group of paediatricians in this area that was aimed at enforcing the international guidelines for antibiotic treatment of respiratory infections in clinical practice. ${ }^{734}$ The educational intervention was mainly based on peer comparison. The notable persistence is quite remarkable and is different from the results that are usually obtained with educational interventions that are limited in time. ${ }^{35}$

Other factors may be associated with the quality of prescribing, for example socioeconomic factors. We already showed in a multiregional study that antibiotic prevalence is higher in low-income areas ${ }^{6 .}$ We compared the amoxicillin index at the ASST level to the average annual income per resident and found that the qualitative profile was likely to be worse in low-income areas (not shown). However, since the Italian NHS is universalistic, being poor or wealthy is unlikely to influence the type of antibiotic prescribed, because parents of children do not have to spend money for antibiotics. Income deprivation in this case may be a proxy of cultural deprivation. ${ }^{36}$ This correlation should be investigated also in countries with private health services. However, we believe that prescribing attitude is the most crucial factor in the heterogeneity found because, even when looking at the same homogenous geographic context, paediatricians had very different qualitative profiles of prescribing. Finally, increasing paediatrician age was one of the factors significantly associated with a better quality of antibiotic prescribing. This finding is unexpected, since most studies on the association between quality of care and physician age were inconclusive or showed that older physician may be at risk of providing lower quality of care.$^{303738}$ This is an important indication of the need for targeting educational interventions especially at the youngest paediatricians.

The main weakness of the study is the lack of the diagnoses. We, therefore, were not able to evaluate the appropriateness of prescriptions. Nevertheless, real world data concerning the access to primary care ambulatories for respiratory infections were used to identify the cut-offs for the quality indicators. We were able to analyse only reimbursed prescriptions, and not private practice paediatricians. However, this fact has a negligible influence on the study, since the aim was to investigate the family paediatricians' quality of antibiotic prescribing. The strength of the study is the possibility to compare the results with previous studies in the overall paediatric population in the same region and to establish the added value of this approach. The results showed that the quality indicators proposed, if further validated, may be a promising tool for benchmarking the antibiotic prescribing trend at the paediatrician level even without knowledge of the diagnoses and could highlight those prescribing behaviours that deviate from the guideline indications.

\section{CONCLUSION}

The quality indicators proposed were able to identify areas of the region, and paediatricians, with inadequate quality of prescriptions. The youngest paediatricians and those who were not exposed to educational interventions showed a significantly worse quality of prescribing.

Paediatricians who were part of a continuous educational programme on the improvement of antibiotic prescribing had a better prescription profile. After further validation, these quality indicators could be a surrogate benchmarking tool for comparing the quality of paediatricians' antibiotic prescriptions, when the diagnosis is unknown, in different settings.

Contributors All the authors contributed equally to the design of the study. DP collected the data and wrote the first draft of the manuscript. MC undertook the statistical analysis. AC contributed in planning the data analysis and in writing the manuscript. AC, AB, IF, LM and MB supervised the study. All authors contributed to and have approved the final manuscript.

Funding This research received no specific grant from any funding agency in the public, commercial or not-for-profit sectors.

Competing interests None declared.

Provenance and peer review Not commissioned; externally peer reviewed.

Open Access This is an Open Access article distributed in accordance with the Creative Commons Attribution Non Commercial (CC BY-NC 4.0) license, which permits others to distribute, remix, adapt, build upon this work non-commercially, and license their derivative works on different terms, provided the original work is properly cited and the use is non-commercial. See: http://creativecommons.org/ licenses/by-nc/4.0/

(c) Article author(s) (or their employer(s) unless otherwise stated in the text of the article) 2017. All rights reserved. No commercial use is permitted unless otherwise expressly granted.

\section{REFERENCES}

1. Belongia EA, Schwartz B. Strategies for promoting judicious use of antibiotics by doctors and patients. BMJ 1998;317:668-71.

2. Pichichero ME, Green JL, Francis AB, et al. Outcomes after judicious antibiotic use for respiratory tract infections seen in a private pediatric practice. Pediatrics 2000;105:753-9.

3. Choonara I. Rational prescribing is important in all settings. Arch Dis Child 2013;98:720.

4. Clavenna A, Bonati M. Differences in antibiotic prescribing in paediatric outpatients. Arch Dis Child 2011;96:590-5.

5. Piovani D, Clavenna A, Cartabia M, et al. The regional profile of antibiotic prescriptions in Italian outpatient children. Eur J Clin Pharmacol 2012;68:997-1005.

6. Piovani D, Clavenna A, Cartabia M, et al. Antibiotic and antiasthmatic drug prescriptions in Italy: geographic patterns and socioeconomic determinants at the district level. Eur J Clin Pharmacol 2014;70:331-7.

7. Cartabia M, Campi R, Clavenna A, et al. Geographical epidemiology of antibacterials in the preschool age. Int J Health Geogr 2012;11:52.

8. Mauri L, Narducci M, Nova A, et al. Primary care paediatrician's antibiotic prescription and self-help use in respiratory infections. Medico e Bambino 2010;29:565-74.

9. de Bie S, Kaguelidou F, Verhamme KM, et al. Using prescription patterns in primary care to derive new quality indicators for childhood community antibiotic prescribing. Pediatr Infect Dis J 2016;35:1317-23. 
10. Nova A, Narducci M, Zanetto F, et al. Systemic antibiotic prescription in family paediatrics health services. Quaderni acp 2008;15:106-11.

11. NICE - National Institute for Health and Clinical Excellence. Respiratory tract infections - antibiotic prescribing. Prescribing of antibiotics for self-limiting respiratory tract infections in adults and children in primary care (Clinical guideline, n. 69). London (UK, 2012

12. Shaikh N, Leonard E, Martin JM. Prevalence of streptococcal pharyngitis and streptococcal carriage in children: a meta-analysis. Pediatrics 2010;126:e557-e564.

13. Shulman ST, Bisno AL, Clegg HW, et al. Clinical practice guideline for the diagnosis and management of group A streptococcal pharyngitis: 2012 update by the Infectious Diseases Society of America. Clin Infect Dis 2012;55:1279-82.

14. Acute otitis media in childhood. Regional guideline. Agenzia sanitaria e sociale dell'Emilia- Romagna, 2015. http://assr.regione.emiliaromagna.it/it/servizi/pubblicazioni/dossier/doss254/at_download/file. (accessed Apr 2017).

15. Howie VM, Ploussard JH. Efficacy of fixed combination antibiotics versus separate components in otitis media. Effectiveness of erythromycin estrolate, triple sulfonamide, ampicillin, erythromycin estolate- triple sulfonamide, and placebo in 280 patients with acute otitis media under two and one-half years of age. Clin Pediatr 1972;11:205-14

16. Lieberthal AS, Carroll AE, Chonmaitree $\mathrm{T}$, et al. The diagnosis and management of acute otitis media. Pediatrics 2013;131:e964-e999.

17. Jacobs MR, Dagan R, Appelbaum PC, et al. Prevalence of antimicrobial-resistant pathogens in middle ear fluid: multinational study of 917 children with acute otitis media. Antimicrob Agents Chemother 1998;42:589-95.

18. Harris M, Clark J, Coote N, et al. British thoracic society guidelines for the management of community acquired pneumonia in children: update 2011. Thorax 2011;66 Suppl 2:ii1-ii23.

19. Esposito S, Cohen R, Domingo JD, et al. Antibiotic therapy for pediatric community-acquired Pneumonia. Pediatr Infect Dis $J$ 2012;31:e78-e85

20. Wald ER, Applegate KE, Bordley C, et al. Clinical practice guideline for the diagnosis and management of acute bacterial sinusitis in children aged 1 to 18 years. Pediatrics 2013;132:e262-e280.

21. Erkoçoğlu M, Kaya A, Civelek E, et al. Prevalence of confirmed immediate type drug hypersensitivity reactions among school children. Pediatr Allergy Immunol 2013;24:160-7.

22. Lange L, Koningsbruggen SV, Rietschel E. Questionnaire-based survey of lifetime-prevalence and character of allergic drug reactions in German children. Pediatr Allergy Immunol 2008;19:634-8.

23. Orhan F, Karakas T, Cakir M, et al. Parental-reported drug allergy in 6- to 9-yr-old urban schoolchildren. Pediatr Allergy Immunol 2008;19:82-5.
24. Anselin L. Local Indicators of Spatial Association-LISA. Geogr Anal 1995;27:93-115.

25. Dik JW, Sinha B, Friedrich AW, et al. Cross-border comparison of antibiotic prescriptions among children and adolescents between the north of the Netherlands and the north-west of Germany. Antimicrob Resist Infect Control 2016:5:14.

26. Holstiege J, Garbe E. Systemic antibiotic use among children and adolescents in Germany: a population-based study. Eur J Pediatr 2013:172:787-95.

27. Youngster I, Avorn J, Belleudi V, et al. Antibiotic use in children - a cross-national analysis of 6 countries. J Pediatr 2017;182:239-44.

28. Pulcini C, Lions $C$, Ventelou B, et al. Indicators show differences in antibiotic use between general practitioners and paediatricians. Eur J Clin Microbiol Infect Dis 2013;32:929-35.

29. Ivanovska V, Hek K, Mantel Teeuwisse AK, et al. Antibiotic prescribing for children in primary care and adherence to treatment guidelines. J Antimicrob Chemother 2016;71:1707-14.

30. Tell D, Engström S, Mölstad S. Adherence to guidelines on antibiotic treatment for respiratory tract infections in various categories of physicians: a retrospective cross-sectional study of data from electronic patient records. BMJ Open 2015;5:e008096.

31. Salvo F, Polimeni G, Moretti U, et al. Adverse drug reactions related to amoxicillin alone and in association with clavulanic acid: data from spontaneous reporting in Italy. J Antimicrob Chemother 2007;60:121-6.

32. Baguley D, Lim E, Bevan A, et al. Prescribing for children - taste and palatability affect adherence to antibiotics: a review. Arch Dis Child 2012;97:293-7.

33. Holstiege J, Enders D, Schink T, et al. Trends in paediatric macrolide use in five European countries-a population-based study. Eur J Clin Pharmacol 2015;71:991-9.

34. Piovani D, Clavenna A, Sequi M, et al. Reducing the costs of paediatric antibiotic prescribing in the community by implementing guideline recommendations. J Clin Pharm Ther 2013;38:373-8.

35. Arnold SR, Straus SE. Interventions to improve antibiotic prescribing practices in ambulatory care. Cochrane Database Syst Rev 2005:CD003539.

36. Sianesi B, Reenen JV. The Returns to Education: Macroeconomics. J Econ Surv 2003;17:157-200.

37. Roy-Byrne P, Russo J, Dugdale DC, et al. Undertreatment of panic disorder in primary care: role of patient and physician characteristics. J Am Board Fam Pract 2002;15:443-50.

38. Choudhry NK, Fletcher RH, Soumerai SB. Systematic review: the relationship between clinical experience and quality of health care. Ann Intern Med 2005;142:260-73. 